\title{
CRONOLOGÍA DE LOS OBISPOS DE CARTAGENA EN LA EDAD MEDIA
}

\author{
JUAN TORRES FONTES \\ Universidad de Murcia
}

\begin{abstract}
SUMARIO
1. Pedro Gallego.- 2. García Martínez.- 3. Diego Martínez Magaz.- 4. Martín Martínez Noloaquisino.- 5. Juan Muñoz Gómez de Hinojosa.- 6. Pedro Gómez Barroso.- 7. Pedro de Peñaranda.- 8. Alfonso Vargas.- 9. Nicolás de Aguilar.- 10. Guillén Gimiel.- 11. Fernando de Pedrosa.- 12. Pablo de Santa María.- 13. Diego de Bedán.- 14. Diego de Comontes.- 15. Lope de Ribas.- 16. Rodrigo de Borja.- 17. Bernardino de Carvajal.- 18. Juan Ruiz de Medina.
\end{abstract}

La historia del obispado de Cartagena sólo cuenta con la que publicó Pedro Díaz Cassou en 1895. Obra comprensiva de las actividades episcopales de cincuenta y nueve obispos, desde fray Pedro Gallego a Tomás Bryan Livermore (1250-1894). En cada capítulo de sus biografiados agrega amplias referencias a cuanto dentro del ámbito eclesiástico y cultural entendía como más apropiado, con novedades de distintos hechos propios de la fase histórica de cada uno de ellos. Se completa con un apéndice de seis capítulos: Fecha conquista de Murcia; traslado de la sede episcopal; construcción de la catedral; fundaciones de Belluga y una Addenda et Corrigenda al año siguiente de su edición.

Este estudio de Díaz Cassou entiendo que cabe calificarlo de meritorio dada la fecha de su publicación, la carencia de amplias fuentes historiográficas de consulta; dificultades de desplazamientos, carencia de Universidad y un largo etcetera. Por ello resulta inadmisible el "presentis-

"Anuario de Estudios Medievales", 28 (1998) 
mo" de quienes la juzgan como si fuera obra de reciente publicación, que en parte se debe a su reedición, la que realmente se consulta, impresa en 1977, sin una sola nota crítica o aclaratoria; reedición innecesaria en estas condiciones y desafortunada, porque confunde a quien la utiliza como base de partida para otros estudios sin tener en cuenta la fecha de su primera edición y dan por cierto lo que con frecuencia es erróneo.

Porque abundan los errores cronológicos, largos vacíos y no se indican las escasas fuentes historiográficas consultadas, e incluso se oculta alguna muy valiosa. Es por ello el que se haga sentir la falta de un Episcopologio actualizado, más que una reedición crítica, porque serían mayores los espacios que ocuparían las notas que el texto. Se ha publicado mucho desde entonces y no faltan amplias colecciones documentales de gran utilidad, y con ellas las obras de Eubel y Gams, así como la de Ubieto para el período medieval. En tanto, esta breve aportación sobre bases cronológicas más firmes como un primer paso.

Tiempos difíciles, problemas múltiples, salvando obstáculos de todas clases, abriendo caminos en gradual y lenta expansión, la Iglesia de Cartagena, resurgida al cabo de largos silencios seculares, cuando doscientos cincuenta años más tarde la Edad Media deja paso a los tiempos modernos, el obispado se hallaba ya plenamente configurado y con adecuada organización en su extenso ámbito territorial. Si bien en esta etapa final del medievo una grave decisión pontificia afectaría a la Iglesia cartaginense: su exención, su dependencia directa de la Santa Sede tras lograr salvar las apetencias metropolitanas de Toledo y Tarragona, se pierde por las insaciables ambiciones de Rodrigo de Borja, Vicecanciller Romano, al subordinar la diócesis de que era titular, pero que nunca conoció, a la de Valencia, que elevaba a rango superior por aquello de disponer también de su dignidad y por amor del paisanaje.

Y la contraposición. Desde 1304, en que se firma la sentencia de Terrellas, la parte septentrional del reino de Murcia pasó a ser gobernación de Orihuela en la corona de los reyes aragoneses. Pero no sucedió lo mismo en el orden eclesiástico, pese a los intentos inmediatos de Jaime II de crear obispado propio, ni tampoco tiempo adelante las naturales aspiraciones oriolanas de romper su dependencia de Murcia, con lo que al cabo del tiempo las relaciones eclesiásticas se hicieron cada vez más difíciles, sin que por ello se rompiera este vínculo diocesano de los prelados de Cartagena para seguir gobernando un obispado extendido sobre dos reinos, no siempre en concordia y en paz. 
Al reino de Murcia y al obispado dos factores negativos les afectarían de forma permanente en el transcurso de estos dos siglos y medio, si bien en gradual disminución. Fue la situación geográfica que hizo del reino una marca fronteriza, un tanto-mucho aislado del resto de Castilla con el señorío de Villena intermedio e interpuesto y con tres fronteras de variada hostilidad: Granada, Aragón y el Mediterráneo, Y por otro, en cierta manera dependiente del anterior, su escasa población, incluso con onerosa disminución de la musulmana, a quienes en principio los conquistadores cristianos les habían asignado la función de seguir trabajando las tierras. Y a los dos hay que añadir los propios medievales: epidemias de peste, plagas de langosta, abundancia de animales dañinos y bandolerismo de todas clases.

Tiempos difíciles los años medievales. Primero al restaurarse la sede episcopal en un reino musulmán vasallo de Castilla y con pactos que impedían modificar o mediatizar las estructuras, formas y religión islámicas. Sería a partir de 1266, desaparecidas las capitulaciones por la rebelión mudéjar, cuando la Iglesia, centrando en Murcia su base creativa y funcional, comienza su progresiva organización, si bien en precario, porque en el resto del reino, salvo contadas poblaciones, todo eran señoríos y encomiendas de las Ordenes militares habitadas por sus vasallos mudéjares, ya que los pobladores cristianos solo se sintieron atraídos a participar en los repartimientos de las ciudades y huertas de Murcia, Orihuela y Lorca, con un polo mas distante, en Alicante por las posibilidades que les ofrecía su puerto y la aventura del Mediterráneo.

A un primer período de asentamiento y de superar dificultades, de configurar su Cabildo y administración con formas cordobesas y sevillanas, la celebración del Sínodo de 1323, en el que se dio a conocer las constituciones del cardenal de Santa Sabina del año anterior en Valladolid, sería pauta y comienzo de un continuado propósito de reforma que se mantendría con desigual proporción en el transcurso de los siglos XIV y XV, pero siempre de indudable provecho en la formación clerical y en la guarda y respeto en su hacer, costumbres y en servicios a los demás.

Los cambios y alteraciones políticas, la guerra civil tan reiterada y diversa, alcanzó y afectó más a los obispos que se vieron involucrados en ellas, que a la Iglesia, porque el Cisma de Occidente no ocasionaría consecuencias directas al desarrollo de la institución eclesiástica. En cambio no todos los prelados pudieron o quisieron sustraerse de participar en las facciones que propugnaban por muy diversas vías alcanzar el poder o en interpretar la línea legítima de la realeza, cuestionadas de forma personal. 
Lo fue con Diego Martínez Magaz frente a Alfonso X y a la ciudad de Murcia. Y, su afecto al infante don Sancho, le sería premiado con largueza cuando, ya rey, Sancho IV le compensaría su fervor político. Semejante camino el de don Nicolás de Aguilar, parcial al conde de Trastámara, tras forzosos servicios a Pedro I. Con otro horizonte y alcance don Fernando de Pedrosa en su enfrentamiento con los Fajardo en la última década del siglo XIV o el obispo Comontes, mediado el s. XV al participar en la contienda promovida por los infantes de Aragón, continuada después por Alonso Fajardo, con duras réplicas epistolares del alcaide lorquino.

En sentido inverso la voluntaria participación en la guerra contra el moro cuando mas necesario era, como don Martín Martínez y su contingente militar, quien tras ganar el castillo de Lubrín, que bautizó con el nombre de San Pedro, oportunamente pudo cambiarlo por los señoríos de Alguazas y Alcantarilla, más el real de Monteagudo y otros bienes que la reina doña María de Molina tenía en el término murciano. Camino más político-militar fue el de don Pedro de Peñaranda al lado de don Juan Manuel y hueste aragonesa en una incursión sobre Vera y valle del Almanzora, mas publicitaria que fructífera, pero testimonial. En esta movilidad bélica, sufriendo sus consecuencias, la expulsión del obispo don Diego Martínez Magaz del reino, reacio a someterse a las disposiciones de Jaime II cuando ocupó el territorio murciano, que le supuso el destierro, aunque los capitulares obtuvieron autorización para cumplir su deseo de ser enterrado en la iglesia mayor de Santa María.

Tres obispos: Borja, Carvajal y Barroso no conocieron su diócesis; otro, Pablo de Santa María solo estuvo breves días en los doce años de su episcopado; posiblemente dos años de sus veinticinco don Lope de Rivas; cuatro de once don Guillen Gimiel y en menor proporción otros, cuyo absentismo estuvo ocasionado por servicios cortesanos o en la curia pontificia que los reyes ordenaron o autorizaron, si bien en contacto permanente con sus vicarios y cabildos. Dedicación plena y fecunda de otros que se mantuvieron en ella hasta su muerte, como los treinta y dos de fray Diego de Bedán; treinta de Martínez Magaz; diecisiete de fray Pedro Gallego; quince de Fernando de Pedrosa y Juan Muñoz; doce Comontes y Vargas; once García Martínez y Aguilar y los diez de don Martín Martínez, sin olvidar los diecinueve de los veintidós de Pedro de Peñaranda.

Por bula "Cum carissimus" el Papa Alejandro IV el 18 de octubre de 1255 ordenaba que se realizara la delimitación territorial del obispado. Debió efectuarse algunos años más tarde, por lo que al recuperarse el reino 
después de la sublevación de los mudéjares, Alfonso X desde Sevilla 11 de diciembre de 1266 otorgaba que el obispado mantuviera los mismos términos que tenía tiempo antes. En líneas generales cabe indicar una línea delimitadora que por Villajoyosa, puerto de Biar e incluyendo a Villena, Almansa, Ayora hasta Cofrentes, bajaba por Chinchilla, Peñas de San Pedro, Lietor, Moratalla, Orcera, Beas, Santiago de la Espada, Huéscar, Galera y cuenca del Almanzora hasta Vera.

Otras fechas destacadas: 1250 restauración; 1291 traslado oficial de la capitalidad de la Sede, que desde 1266 se mantenía en Murcia de hecho; 1391, la eficaz intervención del obispo Pedrosa evitaría que en Murcia se propagara los progroms contra los judíos como sucedió en gran parte de la Península; 1394 con el mismo Pedrosa comienzan las obras para la construcción de la nueva catedral; 1411 durante más de un mes predica Vicente Ferrer logrando beneficiosos resultados; 1467 por bula de Paulo II sería consagrada la iglesia mayor de Santa María en catedral; 12 de enero de 1484 en que se imprime el "Breviarium Carthaginense", al que seguirían tres años después el "Valerio de las historias escolásticas" y la "Copilación de las batallas campales", ambas de Diego Rodríguez de Almela.

Doscientos cincuenta años de seguro y firme caminar, con fases de fuertes impulsos y otras atemperadas a las insalvables dificultades que durante una centuria afligió al reino y a sus habitantes. Enseñanza, cultura, caridad, comprensión en circunstancias adversas y fe en la obra a realizar fueron factores básicos en la configuración de su obispado, plenamente constituído y configurado al finalizar la Edad Media, pero también con permanente aspiración, reivindicatoria, de recuperar el ámbito diocesano anterior a 1266. Fue para ello la obtención de un privilegio rodado de Sancho IV el 4 de octubre de 1293, por el que "damosles para acrecentamiento de su obispado estos lugares que aqui seran dichos: Oria et Cantoria et Moxacar et el valle de Porchena et los Velezes que agora son de moros, que los ayan quando Dios quisiere que sea de Christianos, asy como las aguas vierten de la Sierra de Segura et como lo solian aver en otro tienpo, segund se cuenta en la Coronica vieja". Con perseverancia, reinado tras reinado, la Iglesia pudo ver confirmado este privilegio hasta los mismos Reyes Católicos, quienes años después por razones de Estado, en las fechas propicias de sus conquistas, no quisieron o no pudieron cumplir sus promesas. Un sueño de siglos, un señorío en el aire. 


\section{Pedro Gallego, 31-VII-1250 a 19-X-1267}

Natural de Santa Marta de Ortigueira, Provincial de la Orden Franciscana de Castilla (1236), Confesor del infante don Alfonso y emisario suyo y de Fernando III ante Inocencio IV con la procuración de lograr la restauración de la Sede Cartaginense, a tenor la Bula "Virtutum Dominum" relativa a la dotación de nuevas sedes. Dos años transcurrieron hasta que por la bula "Spiritus exultante" de 31 de julio de 1250, Inocencio IV llevaba a efecto su restauración. Y con ella y en el mismo día el nombramiento y consagración de fray Pedro Gallego como obispo de Cartagena. Por su parte el monarca castellano dotaba a la nueva Iglesia con diez mil monedas de oro anuales, situadas en las rentas reales que se obtenían del vasallaje musulmán. No mucho después, ante las pretensiones metropolitanas de Toledo y Tarragona, la decisión pontificia de declararla sede exenta, con dependencia directa de la Sede Apostolica, permitiría el libre desenvolvimiento del renacido obispado.

Venciendo dificultades, pues solo Cartagena, Mula y Alicante se hallaban bajo directo dominio castellano e imposibilitado en el resto del reino por los convenios establecidos con los musulmanes al establecer el Protectorado, fray Pedro Gallego pudo ir efectuando lentamente la instauración de su Iglesia siguiendo el módulo cordobés. A la vez colaboró en la labor cultural alfonsí, con la traducción del árabe al latín de obras de filósofos griegos, hasta que en 1266, con la recuperación del reino tras la rebelión mudejar, pudo extender su labor apostólica en todo el obispado. Víctima de una epidemia de pestilencia moría al año siguiente en Cartagena.

\section{García Martínez. Electo, 1267-1278}

Deán del Cabildo murciano en 1266, eficaz colaborador de fray Pedro Gallego, propuesto por el Cabildo como electo, en el mismo año 1267, como "Electo" se mantuvo al frente del Obispado hasta 1278 en que cesó; por renuncia según Eubel, por anulación de su elección por Nicolás III como indica O'Callaghan al nombrar nuevo prelado; doce años de gran actividad y eficaces servicios a la Iglesia y sobre todo como juez partidor de los Repartimientos de las huertas de Murcia, Lorca y Orihuela. Lo que permitiría cambiar la dotación de diez mil maravedís anuales por seiscientas cincuenta tahúllas en las mejores tierras de la huerta murciana. También, con 
ayuda real obtendría la efectividad en el pago del diezmo eclesiástico en señoríos y encomiendas militares de todo el reino; donación de tahúllas a los diecisiete clérigos parroquiales, y adaptación de las mezquitas en iglesias. De hecho, la capitalidad de la sede episcopal en Murcia, su solicitud de hacerlo con carácter oficial fue atendida por Nicolás III al ordenar se abriera información sobre la situación del reino.

\section{Diego Martínez MagaZ. 23-XII-1278 a 16-XI-1300}

Factor decisivo en el episcopado de don Martín, tiempo antes arcediano de Cerrato, fue su adhesión a la política del infante don Sancho en contra de la firme decisión del concejo de Murcia, fiel a Alfonso X hasta su muerte. La que Sancho IV premiaría con la concesión de un gran número de privilegios para su Iglesia: exención a los clérigos de moneda forera y de servicios ciudadanos; cesión de mezquitas y sus alhoces en disputa con el Concejo; donación de todos los bienes que habían pertenecido al monasterio cisterciense de la Santa María la Real y con perspectivas de futuro, todo cuanto había sido donadío del infante don Felipe en su señorío de Purchena, que se extendía hasta la cuenca fluvial del Almanzora, abandonado desde 1266 después de la sublevación mudéjar por imposibilidad de su repoblación y defensa.

En 1291, con autorización de Sancho IV y previa bula pontificia de Nicolas IV de 1289, se trasladaba oficialmente la capitalidad de la sede episcopal a Murcia, en donde estaba de hecho desde 1267. Espectador y sufrido impaciente de la invasión del reino por Jaime II, que le costó la expulsión de su obispado. El 22 de diciembre de 1300 autorizaba Jaime II el traslado de sus restos a la iglesia de Santa María la Mayor de Murcia.

\section{Martín Martínez Noloaquisino. 5-XII-1301 a 30-IV-1311}

A la muerte de don Diego Martínez Magaz, Jaime II que seguía manteniendo su dominio en el reino de Murcia, prohibió al Cabildo murciano la elección de nuevo obispo hasta su llegada a la capital. Suspensión para escribir, en enero de 1301, a Bonifacio VIII en solicitud de que nombrara obispo que no le fuera hostil. Fue designado don Martín Martínez Noloaquisino, arcediano de Nájera, pero el enfrentamiento Castilla-Aragón 
retrasaría su llegada. En noviembre de 1302 era el canónigo Juan Domínguez, deán y vicario general quien gobernaba la diócesis en difíciles condiciones. Cabe deducir que hasta 1304 no ocuparía su sede prelaticia don Martín Martínez.

Si la paz hizo desaparecer los agravios de la ocupación, también llevó consigo abundante número de problemas: evitar la segregación del obispado de cuanto había sido anexionado a Aragón y a la vez actitud conciliadora y objetiva con la gobernación de Orihuela, sus rentas, sus clérigos y sus políticos. Obtendría de Fernando IV nuevos privilegios, entre ellos exenciones para sus clérigos; el diezmo del ganado trashumante y confirmación de los privilegios de la Iglesia hispalense. A su vez correspondió a la política de Fernando IV organizando una hueste en la guerra de Granada, que en 1309 ocupó el castillo de Lubrín, pero su situación avanzada e insegura, le impedía su defensa, por lo que obtuvo su cambio por Alcantarilla y Alguazas, señoríos de la reina doña María de Molina. Sería sepultado en su tierra natal "Tudellam de Navarra".

\section{JUAn MuÑoz Gómez de Hinojosa. 6-XI-1311 a 8-X-1326}

Deán del Cabildo murciano, su episcopado se extiende en los años de minoría de Alfonso XI. A la lenta recuperación del reino, a causa de la mísera situación en que quedó el reino en 1304, se sumaría la sucesión de inquietos períodos de tiempo a causa de los enfrentamientos Murcia-don Juan Manuel, apoderado éste de gran parte del adelantamiento. En 1321, a la muerte de doña María de Molina, se hizo efectiva la posesión de los señoríos de Alguazas y Alcantarilla, real de Monteagudo, casa y baños en Murcia.

En 1315 ampliaba el Cabildo con seis dignidades, ocho canónigos y doce porcioneros. Las Constituciones del cardenal de Santa Sabina, aprobadas en el concilio de Valladolid en 1323, decisiva para la reforma de la Iglesia, serían hechas efectivas en el Sínodo celebrado en Murcia al año siguiente. En 1326 don Juan Muñóz pasó a la diócesis de Calahorra, donde se le denominaría Juan de Santo Domingo, porque vivió, murió y fue enterrado en Santo Domingo de la Calzada el 21 de enero de 1346. 


\section{Pedro Gomez Barroso. Prec. 3-IX-1326 a 18-XII-1327}

Nieto del poeta Pedro Gómez Barroso, sobrino de Gonzalo García Gudiel, arzobispo de Toledo, en el poco tiempo que oficialmente fue obispo electo de Cartagena, coincidió con Pedro López de Ayala, casado con Sancha Gómez Barroso, al que Alfonso XI puso al frente del adelantamiento de Murcia por rebeldía de don Juan Manuel.

No parece que pisara tierras murcianas, porque en 22 de julio de 1327 en que se firmó una composición sobre aniversarios, la firmaban los dos vicarios generales de don Pedro "electo", quien cinco meses más tarde era elevado al cardenalato con el título de Santa Práxedes. Sería legado pontificio en los años siguientes en Castilla y después en misiones pacíficas relacionadas con el Cisma y el Imperio. En 1341 pasó al título de cardenal de Santa Sabina, y siete años más tarde muere en Aviñón.

\section{Pedro De Peñaranda, 23-XII-1327 a Julio de 1349}

No llegó a Murcia hasta 1329, pues el 23 de agosto le recomendaba Alfonso XI "es limosna mia e de aquellos onde yo vengo... e agora va alla a su obispado a cantar misa nueva e fazer otras cosas que pertenescem a su oficio como obispo", pero avisando "a se tornar luego para mi servicio". Si volvió a la corte real debió ser por poco tiempo, pues en 1330, con autorización real, compraba heredades para fundar dos capellanías.

Logró cierto entendimiento con don Juan Manuel, por lo que hubo recelo en Murcia, y le negaron la entrada en la ciudad, hasta que por carta Alfonso XI afianzó su honradez y fidelidad, con lo que se disiparon las dudas. Participaría en la guerra de Granada a satisfación real, aunque también su diócesis sufriría dos duras incursiones granadinas.

Celebró sínodos en 1331, 1332, 1341 y 1344. Tuvo dificultades con Orihuela y con el Concejo murciano, y su excesivo rigor ocasiono la intervención real ordenándole levantara las censuras eclesiásticas en algunos casos. En su haber cuenta también las obras en Santa María la Mayor, adaptando parte de la vieja mezquita con la construcción del coro y claustro, así como un campanil; a lo que se suma torres en Lorca y Alguazas. Su fallecimiento, a igual que su nombramiento, motivó carta de Alfonso XI de 10 de julio de 1349 , enviada con un alcalde real que acudía a haberse cargo 
de los bienes de don Pedro "que agora fino". Según Comontes "jacet in dicto choro coram cathedra episcopali".

\section{Alfonso De VARgas, 24-VII-1349 a 4-VIII-1361}

Su episcopado tiene lugar en años difíciles, pues a las terribles consecuencias de la Peste Negra, seguirían los primeros años del complejo y contradictorio reinado de Pedro I. En la defensa de los vasallos mudéjares de sus señorío de Alcantarilla y Alguazas, así como en la percepción del diezmo eclesiástico encontró la ayuda del rey don Pedro, en cambio hubo dura contienda entre las "conpañas del obispo e otros de Murcia" del adelantado. Ambos, adelantado y obispo fueron obligados a presentarse en la corte real.

Si encontró la ayuda de Pedro en la cuestión de los diezmos, en cambio tuvo que aceptar y cumplir el ordenamiento de Cortes respecto a juzgar a los que se decían clérigos y no lo eran. También con Orihuela, sobre el cobro de censos y la requisa de trigo en los almacenes eclesiásticos, lo que le obligó al entredicho para su recuperación. Mas adelante en la guerra de los dos Pedros no pudo evitar nuevos embargos, aunque tenaz lograría su recuperación. Sínodos en 1352 y 1361, todos referentes a mejorar el orden eclesiástico. El 4 de agosto de 1361 era trasladado a Avila.

\section{Nicolas de Aguilar, Prec. 4-VIII-1361 a OCTUbre 1372}

Si en los comienzos de su episcopado mantuvo buenas relaciones con Pedro I, después, como tantos otros, abandonó la bandera petrista y con Lopez de Ayala huyó a Aragón; el 29 de abril de 1367 Pedro I hacía público la deserción de ambos y la orden de embargar sus bienes y rentas. López de Ayala moriría luchando en la frontera, Nicolás de Aguilar pudo volver a su diócesis y obtuvo de Enrique II la confirmación de todos los privilegios de su Iglesia y el agradecimiento a sus valiosos servicios.

Sínodos en 1362 y sobre todo en 1365 con ampliación del cabildo, mayores atribuciones del Vicariato general, que representaría al obispo con plena autoridad, e incluso la facultad de escoger entre ellos nuevo obispo. Disposiciones que serían reunidas en su "Fundamentum Ecclesiae", publicadas en 1756 por el obispo Rojas. 
En 1367 autorizaba a la abadesa de Santa Clara para construir monasterio e iglesia en las casas reales concedidas por Pedro I, así como para pedir limosna para costear dichas obras. A la vuelta de su destierro, nuevo sínodo en 1370 con referencias a las horas canónicas; doble bendición a los que contraían matrimonio; no se cobrara nada a los que se confesaban; sobre finados y entierros. Según Comontes "ubi jacet in capella Capitulari Claustri, ad manum sinistran altari”.

\section{GUILLÉN GIMIEL, 24-XI-1372 A 1383}

Influencias pontificias facilitarían el nombramiento de don Guillén Gimiel, quien retrasó tanto tiempo la toma personal de su prelatura que motivó dura queja de los murcianos ante Enrique II: "El Papa Santo proveyo desta Iglesia de Carthagena por obispo a don Guillen, que es frances e clerigo de su consistorio, e quel dicho obispo que esta e faze su morada en Aviñon, e envio por su vicario a un frances e por recabdar sus rentas. E quanto puede aver que ge lo troca en oro e en plata e enbiagelo a Aviñon, e que cunpliere mas a servicio de Dios e nuestro e onrra dese obispado e de vosotros que estudiere y". "Enrique II aseguró que rogaría al Papa para que acudiera a su diócesis.

En tanto el monarca apreciando tal circunstancia, envió un obispo auxiliar para atendiera a sus diocesanos. Ya en Murcia, don Guillén fue obispo riguroso en la defensa de los intereses de la Iglesia y en el cumplimiento de sus normas. El Cisma y la diversidad de obediencias, le enfrentaría con sus diocesanos de Orihuela, y si no vaciló en decretar penas canónicas contra la ciudad y algunos de sus gobernantes, después logró establecer concordias que mejoraron las relaciones. Su nombramiento en 1383 de cardenal le alejó definitivamente de Murcia. Sínodos en 1375, 1377, 1380 y 1382 .

Al reconocer el obispo Nicolás de Aguilar el derecho del cabildo a la elección entre sus miembros de nuevo obispo, en 1383 fue elegido el chantre Gonzalo González, quien se dirigió a la Corte real en solicitud de su apoyo ante el Papa, pero Clemente VII se había adelantado nombrado a Fernando de Pedrosa, obispo entonces de Ciudad Rodrigo. 


\section{Fernando DE PEdRosa, 12-XII-1383 a DiCIEMBRE DE 1399}

Los dieciseis años de su episcopado comprenden dos periodos de distinta faz. Los ocho primeros con actuaciones propias de dirección, orientación y de su superior cultura, así como concordia de sus diocesanos de Murcia y Orihuela. Destaca su labor extraordinaria, con felicitación real para impedir la matanza de judíos y moros; en igual sentido su eficaz intervención en la epidemia de peste que ocasionó sólo en la capital 6.080 muertos. A el se debe igualmente la iniciación de las obras de la catedral en los comienzos de 1394.

Cuestiones familiares, la boda de su hermana Beatriz con Juan Sánchez Manuel y las ambiciones de éste le involucraron en la larga contienda entre "Manueles y Fajardos"; siendo acusado injustamente ante Enrique III, cuyos regentes hubieron de rectificar algunas disposiciones tomadas contra sus bienes y rentas. Lo mismo sucedería ante la Corte pontificia, de la que obtuvo semejantes satisfaciones. Sínodos en 1384, 1385, 1389, 1392 y 1395. La exigencia en el pago de "catedrático" ocasionaría también larga controversia.

Comontes nos dice "Sepultus hic Murciae in dicto opere novo, in capella quam in capite ipsius operis sub invocationes Beati Hieronymi inceperat, et semifactam reliquerat, ubi in terra plana jacet humiliter tumulus".

\section{Pablo de Santa María, 30-VII-1403 a 18-XII-1415}

Sede vacante tres años por la división del Cisma y falta de obediencia, permitirían al Cabildo la elección del canónigo López de Dávalos, hermano del Condestable Ruy López de Dávalos como obispo - lo sería más tarde de Córdoba-, pero el reconocimiento de Benedicto XIII le facilitaría el nombramiento de Pablo de Santa María. Obispo absentista - parece que sólo estuvo en Murcia en 1408- ya que su cargo de canciller mayor y consejero del regente Fernando de Antequera le mantendría en la Corte. Ausente pero preocupado por su diócesis. Extremado en la imposición de penas canónicas a veces injustas en su particular defensa de los vasallos mudéjares de Alcantarilla, así como en Orihuela, motivaría en algún caso la intervención del Regente, pues, además, sus sanciones se materializaban en 
económicas para emplearlas en la construcción de la Catedral, con exposición de quejas de los agraviados.

El 19 de enero de 1411 llegaba su maestro Vicente Ferrer a Murcia. Un mes en la ciudad y otro en el reino en su actividad misionera ocasionaría fecundas consecuencias, y de mayor trascendencia sería la ordenanza aprobada por el Concejo murciano, que mas tarde se haría pública para toda Castilla por la reina doña Catalina, en la relación de cristianos, moros y judíos. Hubo gran número de conversiones y tras ellas, tiempo adelante el problema de la sinceridad de estas conversiones. Sínodos en 1406 y 1409. El 18 de diciembre de 1415 era designado obispo de Burgos.

\section{DIEGO DE BEDÁN, 18-XII-1415 A 22-V-1447}

Episcopado prolongado y fructífero, decisivo para la obra de Santa María la Mayor, tanto como para que dos décadas después de su muerte pudiera ser consagrada en Catedral. Obispo de Badajoz desde 1409, por causas que ignoramos fue destinado a Plasencia en 1422 y designado Guterio Gómez, del que nada sabemos, si que el 1 de octubre de 1423, exactamente un año, fray Diego de Bedán volvía a Murcia si es que de ella había salido.

Su experiencia, integridad moral y eficaz labor se hicieron sentir en el cumplimiento de sus deberes episcopales pese a su vejez y dolencias, tal, que pudo lograr a su tercera solicitud que el Concejo le autorizara a construir un andamio sobre la calle real para poder pasar desde su residencia, a escasos metros, para "oir las oras"; esto en 1429. También lo mismo que su antecesor, o superándolo en la imposición de penas pecuniarias, a veces elevadas y destinadas a las obras de la catedral ocasionaron, especialmente en Orihuela un antagonismo que incrementaría el propósito de creación de obispado propio.

Durante estos años crecen las capillas hasta alcanzar los pilares dextrales del crucero, pero su decrepitud exigiría la estancia de un obispo no residencial, hasta el nombramiento como coadjutor de su sobrino el deán Comontes y aceptar el título de arzobispo de Césarea, falleciendo al año siguiente a los ochenta y cinco años de edad. Sería enterrado en su capilla de San Francisco y San Antonio, aunque años más tarde sus restos fueron trasladados a Mayorga de Campos, su tierra natal. 


\section{DiEgo DE COMONTES, 1-IV-1446 A 6-III-1458}

Los doce años como obispo y algunos anteriores como deán y coadjutor se sucedieron en un periodo histórico altamente conflictivo, porque todo entonces se mantuvo centrado en torno a la figura del famoso Alonso Fajardo, alcaide de Lorca, enfrentado a su primo el adelantado Pedro Fajardo. No sería reconocido en Murcia hasta el 29 de diciembre de 1449, cuando en la iglesia de Santa María de Molina se firmó una composición general de paz. Por ello pudo entrar en la capital en 1450 y hacerse cargo de su diócesis, alejándose ya de las cuestiones y enfrentamientos de los Fajardo.

Se mantuvo con distinto ritmo las relaciones con Orihuela, pues si en principio fueron aceptables, pronto surgieron las protestas y supuestos agravios y vejaciones que volvieron tensar una concordia cada día más difícil. En tanto las obras de Santa María crecían, que se menciona ya como catedral en 1458.

Comontes fue autor de una obra importante: "Fundamentum Ecclesiae Carthaginensis", suma de disposiciones muy diversas y relación histórica de sus antecesores con desigual atención a cada uno de ellos.

\section{LOPE DE RIBAS, PREC. 14-III-59 A 5-II-1480}

Prior de Osma, consejero real y sobre todo capellán de la reina doña Juana, fue, como cortesano, absentista. Recibido en Murcia con cartas de Enrique IV y de doña Juana elogiosas en que se admitía la posibilidad de darle "licencia por algunos días". Lo cual supuso que desde 1459 a 1474 se mantuviera en la Corte, ya que en este año se dijo en Murcia que "es la primera vez que viene". Pero en 1476 se ausentó definitivamente porque los Reyes Católicos le nombraron Presidente de la Santa Hermandad, en que se mantuvo hasta su muerte. El 6 de marzo de 1480 los Reyes ordenaron secuestrar sus rentas por cuanto "es fallescido e pasado desta presente vida, por cuyo fin e muerte el dicho obispado quedo vaco".

En estos años llegó la paz al reino de Murcia y signo de los nuevos tiempos el Concejo donaba a la Iglesia dos artilugios de guerra para la obra de Santa María y la lombarda mayor, para que de la venta de su hierro pudiera hacerse una campana para el reloj que se instalaba en el campanil de Santa María. 
El canónigo y cronista Diego Rodríguez de Almela lograba en Roma el 24 de enero de 1465 bula de Paulo II para la consagración de la catedral, que se efectuaría en su capilla de la Visitación el 20 de octubre de 1467. Nuevas capillas y mejora de las relaciones con Orihuela serían avances en el desarrollo de la Iglesia Cartaginense, y con repetición de disposiciones sinodiales para la mejora del clero, siempre recordatorias en gran parte de la constitución de Valladolid del siglo anterior.

\section{RODRIGO DE BORJA, 8-VII-1482 A 11-VIII-1492}

Una década en la que el obispado de Cartagena no conoció a su prelado, quien, con el cual se manifiesta como mal ejemplo el doble concepto de oficio y beneficio. Hasta 1489 no envió a dos familiares con plenos poderes para el gobierno de la diócesis. No fue sólo perjudicial su absentismo, sino que en 9 de julio de 1492 lograba de Inocencio VIII, al que sucedería en el solio pontificio un mes mas tarde, la elevación a metropolitana de la iglesia de Valencia, de la que era obispo, dándole como sufragáneas los obispados de Cartagena y Mallorca. Tal disposición hacía desaparecer la exención que tenía la Iglesia de Cartagena desde su restauración en 1250, lo que provocó la airada protesta de elevado número de regidores ante los Reyes Católicos, a quienes suspendieron en sus oficios por mas de diez años.

En 1488 llegaban a Murcia los Reyes Católicos y conocieron las obras de la Catedral y privilegiaron al maestro Pedro de Ávila, autor de la portada de los Apóstoles con exención de tributos, al mismo tiempo que confirmaban los de Diego Sánchez de Almansa, maestro mayor de la catedral. Influenciada por ello, dos años mas tarde por disposición de Luisa Fajardo, comenzaba su marido Juan Chacón la construcción de una nueva capilla, ya con el nuevo estilo a tenor de los tiempos y medios económicos del adelantado, que terminaría su hijo Pedro Fajardo Chacón, marqués de los Vélez, en 1507.

\section{Bernardino De CARvajal, 27-III-1493 a 20-II-1495}

No acudiría a su obispado. Su actividad romana al servicio de los Reyes Católicos en la Corte pontificia se lo impediría, pero si facilitó su paso de la mitra de Badajoz a la de Cartagena en 1493, con plena ausencia 
en uno y otro obispado, en cierta manera propio de la época y de los elegidos; más aún cuando seis meses más tarde fue elevado al cardenalato con la titularidad de Santa Cruz. No extraña que en febrero de 1495 fuera designado obispo de Sigüenza y dejara paso libre a su sucesor Juan Ruíz de Medina. Conscientes de cuanto significaba su ausencia, los Reyes Católicos la suplieron en materias en que podían intervenir con cartas y disposiciones a su Provisor y de igual manera al Vicario general.

\section{JUAN RUIZ DE MEDINA, 20-II-1495 a 16-III-1502}

Consejero real con actividad diplomática al servicio real en Francia y en Roma con el conde de Tendilla, y mas tarde gobernador general de Castilla durante la guerra de Granada; obispo de Astorga, después de Badajoz, todavía se encontraba en Roma en 1497. Envió como Provisor a Alfonso de Mariana, arcediano de Páramo. Según Díaz Cassou no llega a Murcia hasta 1499 y era trasladado a Segovia en 1502. Ausencias prolongadas, justificadas y exigidas por la realeza, serían suplidas por los respectivos Vicarios, personas de confianza, pero que por ello irían adquiriendo mayores prerrogativas y en algún caso revocando algunas constituciones sinodiales anteriores atemperándolas a las nuevas formas de vida y a otros conceptos mas acordes con la marcha de los acontecimientos, a la vez que ciertos conflictos con los oficiales del Santo Oficio, que ampliaban su jurisdicción de forma injustificada.

De las disposiciones sinodiales aprobadas en este episcopado cabe señalar la ratificación de las fiestas de guardar, tal como lo había dispuesto don Lope de Ribas, si bien es significativo que a la penalización con excomunión a quienes no las observaban, se sustituye ahora por pena pecuniaria, un real. Fiestas que era muchas, aparte de los domingos. Los apóstoles Pedro, Juan, Santiago, Andrés, Felipe, Tomás, Bartolomé, Mateo, Santiago de Alfeo, Simón, Judas y Matías, así como Pablo, Lucas, Esteban, Bernabé, Lorenzo, día primero de Navidad, Circuncisión, Epifanía, Purificación, Anunciación, Invención de la Cruz, Natividad de San Juan, Corpus, María Magdalena, Transfiguración, Asunción, San Miguel Arcángel, Natividad de la Virgen, Todos los Santos, Concepción, Resurreción, Pascua del Espíritu Santo, Fiesta del Sacramento. 


\section{RÉSUMÉ}

L’histoire médiévale de l'évêché de Carthagène embrasse deux-cent-cinquante ans. Dix-sept prélats et un élu, non confirmé au bout d'onze ans, ont maintenu leur titulrité avec une inégale et différente dédicace, car l'absentisme en manqua pas et quelques-uns n'ont même ps foulé le sol de Murcie.

Ampleur territoriale et pendant deux siècles étendu sur les royaumes d'Aragon et de Castille. avec ses séquences économiques et sociales et des différences d'ordre politique. Notre apport est de fixer la chronologie et les faits les plus significatifs de chaque épiscopat.

\section{SUMMARY}

Mediaeval history of Cartagena's Diocese spans two hundred and fifty years. Seventeen prelates and an elected one,unconfirmed after fifteen years, kept position with uneven dedication and zeal, partly due to absenteeism and also to the fact that some of them never set foot on Murcian terrtory. This vast diocese spread further into the Castilian and Aragon kingdoms for two centuries bringing about socio-economic and political changes. Our contribution here consistis of establishing the chronology and the most significant of the appointed bishops during those hundred and tifty years. 